\title{
Development of Soy Milk Based Functional Fruit Yogurt Fortified with Extra Virgin Olive Oil
}

\author{
Md. Wadud Ahmed, Md. Sharifur Rahman
}

\section{ABSTRACT}

Cardiovascular diseases (CVD) and obesity are the most increasing world health challenge in recent days. To prevent these health problems, food researchers are intensively focusing to replace animal fat by healthy vegetable item with incorporation of different bioactive compounds. This study was conducted to develop a novel yogurt using different ratio of soy and cow milk. Blueberry pulp, extra virgin olive oil and stevia were used in the bottom portion to enhance functionality of the developed yogurt against CVD. All developed yogurt samples were analyzed for taste, texture and overall acceptability. Sensory analysis showed that, the yogurt developed from $75 \%$ soy milk and $25 \%$ cow milk had the highest overall acceptability.

Keywords: Blueberry, extra virgin olive oil, functional yogurt, soy and cow milk.
Submitted : June 15, 2021

Published : July 06, 2021

ISSN: $2684-1827$

DOI: 10.24018 /ejfood.2021.3.4.325

\section{Md. Wadud Ahmed*}

Department of Agricultural Engineering, Faculty of Agriculture, Sher-e-Bangla Agricultural University, Bangladesh. (e-mail: wahmed@sau.edu.bd) Md. Sharifur Rahman

Department of Food Technology and Engineering, Faculty of Nutrition and Food Science, Patuakhali Science and Technology University, Bangladesh. (e-mail: sharif ${ }^{\circledR}$ pstu.ac.bd)

*Corresponding Author

\section{INTRODUCTION}

Yogurt is a widely consumed fermented dairy product in which proteins coagulated by lactic acid producing bacteria [1]. Most peoples prefer yogurt over normal milk due to its easily digestible protein, availability of probiotics and bioavailability of different minerals and vitamins [2]. Day by day, the yogurt getting different forms in relation to different health benefits. Though the dairy milk is the main ingredient of yogurt but due to its some negative health aspects vegetables based milk items are also using to produce yogurt [3]. In addition to prebiotic and probiotic ingredients, scientists now suggesting for lowering or replacing the dairy fat of the yogurt. The use of soy milk in yogurt product has increasing mainly for its lower fat and higher protein content [4]. Moreover, less saturated fatty acids, absence of lactose and high amino acid profile gives more consumer preference to the soy milk based food products [5]. A developed bioyogurt from the mixture of $25 \%$ soy milk $+75 \%$ cow and buffalo milk showed very good nutritional and health benefits [1]. Compare to dairy milk, low price of soy milk is also one of the major reasons of expanding soy based food production [6]. However, some consumers do not prefer soya based items due to its unpleasant flavor [1]. This problem can be solved adding fruit pulp or flavoring agent. The consumption of blueberries (Vaccinium corymbosum) in different fermented food items has increased due to rich source of bioactive compounds [7]. It has been proven that berries are considered as disease fighter food as it has anticancer, antioxidant and anti-mutagenic power [8]. Although consumption of strawberries is more common in fruit yogurt production, use of blueberries also getting popularity with addition of some sweetening or flavoring ingredients [7]. In addition to health benefits, blueberry's distinctive color gives an extra attraction to the developed product. Incorporation of different plant or marine based oil rich in monounsaturated fatty acids (MUFA) and polyunsaturated fatty acids (PUFA) in fermented food is also getting popularity aimed to develop different functional food [9][11]. Strawberry yogurt with addition of microencapsulated salmon oil rich in n-3 fatty acid has shown high acceptability to health conscious consumers [11]. Five different vegetable oils were used to get PUFA rich functional yogurt to replace plain yogurt [10]. As well as other vegetable oil, extra virgin olive oil (EVOO) is extensively used for production of Nano-emulsion and new food development [9]. Regular consumption of EVOO improves the antioxidant status and reduce the LDL content of blood due to its phenolic content [12]. In addition to CVD prevention, olive oil is very effective against breast cancer and type II diabetes mellitus [9]. To fight against CVD, olive oil especially EVOO play a great role due to its higher MUFA, PUFA and other bioactive compounds [13]. In replace to sugar (sucrose), stevia (artificial sweetener) is also an excellent idea to get low calorie yogurt. Stabilizer (pectin, alginate, gelatin etc.) can be used to get a good texture. Modified starch, carrageenan or another hydrocolloid stabilizer is also used to prevent floating of any ingredient thus to get better consistent and acceptable product [6]. 
Therefore, based on previous discussion, the objective of this study was to develop a consumer acceptable novel functional yogurt using different combination of soy milk and cow milk with incorporation of blueberry pulp and extra virgin olive oil.

\section{MATERIALS AND MethodS}

\section{A. Raw Materials}

The experiments was conducted in the kitchen lab of the department of Agricultural Engineering, Sher-e-Bangla Agricultural University, Bangladesh. Soy milk, low fat cow milk, blueberry pulp, extra virgin olive oil, stevia, vanilla flavor, agar powder, Bifidobacterium starter and sugar were purchased from a local super shop.

\section{B. Preparation of Fruit Compote}

Locally purchased blueberry pulp (50\%) was mixed with table sugar $(25 \%)$ and stevia $(2.5 \%)$. After addition of required amount of water the mixture was pasteurized at $95^{\circ} \mathrm{C}$ for 3 minutes. $22.5 \%$ agar powder and $2.5 \%$ (by volume) EVOO were mixed at the end of pasteurization. Finally the prepared fruit compote (bottom portion of the final yogurt) was mixed properly and poured into individual cup and kept in refrigerator after cooling.

\section{Preparation of Yogurt}

Five different soy and cow milk combination were used for yogurt manufacturing is shown in Table I.

TABLE I: AMOUNT OF SOY AND COW MILK FOR YOGURT PREPARATION

\begin{tabular}{ccc}
\hline \hline Sample & \%Soy Milk & \% Cow Milk \\
\hline 1 & 100 & - \\
2 & - & 100 \\
3 & 25 & 75 \\
4 & 50 & 50 \\
5 & 75 & 25 \\
\hline \hline
\end{tabular}

Low fat cow milk and soymilk were mixed properly following stated ratio. The mixture was pasteurized $85^{\circ} \mathrm{C}$ for 10 minutes. Vanilla flavor was added at the end of pasteurization and cooled to $42^{\circ} \mathrm{C}$. After addition of Bifidobacterium starter, the mixture poured into glass cup which are bottom filled with previously prepared berry fruit compote. Finally the inoculated yogurt left in an incubator at $42( \pm 1){ }^{\circ} \mathrm{C}$ for 8 hours.

\section{Measurement of $\mathrm{pH}$}

The incubated yogurt samples were checked for $\mathrm{pH}$ during 8 hour fermentation period using a digital $\mathrm{pH}$ meter. The initial $\mathrm{pH}$ of all samples was in the range of 6.9 to 7.1 .

\section{E. Sensory Analysis}

Developed fruit bottom yogurt samples were used to sensory analysis by 25 semi trained panelists using a 9 point hedonic scale. The panelists comprised of both female and male members who are in 25 to 30 age range. Taste (flavor), texture (consistency) and overall acceptability were evaluated at room temperature. Yogurt was served to panelists in plastic cup coding with single digit and requested to score the samples as 1-3 (low), 4-6 (medium) and 7-9 (high). Score 1 implies lowest quality (bad) while score 9 imply best quality (excellent). To prevent biasness in scoring the sensory evaluation was performed in individual basis.

\section{RESUlT AND DISCUSSION}

\section{A. Product Description}

The developed fruit bottom yogurt is shown in Fig. 1. It was observed that, there was uniform mixture of yogurt in which soy milk proportion was comparatively less than cow milk. This may be due to less binding of soy protein with casein.

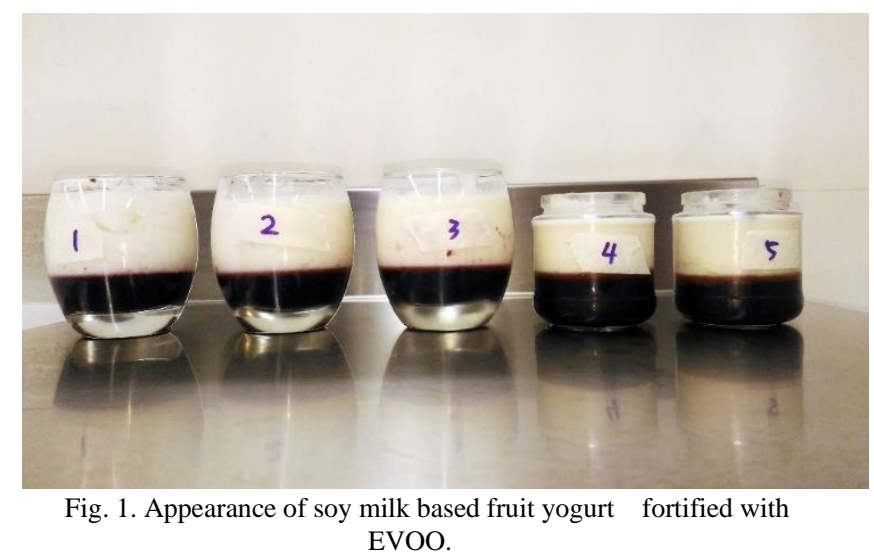

Yogurt from $25 \%$ soy with $75 \%$ cow or buffalo milk was reported to be best for uniform mixing and other point of physical judgment [1]. Uniform mixing of soy yogurt with added rice bran oil was also reported [3]. Even though the yogurt had uniform mixture but some coarse particle was observed in fruit compote in bottom portion of the yogurt cup. This may be due higher gravitational force of coarse particles which results from non-uniform pulping of berry fruit. This problem can be solved by uniform blending followed by a proper straining of fruit pulp.

\section{B. Kinetics of Acidity during Fermentation}

The $\mathrm{pH}$ content of yogurt samples (only upper yogurt portion, not fruit bottom) were determined at each one hour interval basis. At the same measuring time, the $\mathrm{pH}$ value of all samples were quite nearer while there was no significant difference was observed due to different soy milk ratio. Maximum difference was observed between yogurt from $100 \%$ cow milk and yogurt from $100 \%$ soy milk. However, in all samples, $\mathrm{pH}$ drops was faster during first 3 hours of fermentation then followed by a slower decrease. The fall of $\mathrm{pH}$ of yogurt from $25 \%$ cow milk $+75 \%$ soy milk is shown in Fig. 2.

It can be seen that $\mathrm{pH}$ drops to 4.5 within first 6 hours of incubation. Similar observation was also found where a $\mathrm{pH}$ of 4.6 was recorded for soy yogurt with addition of inulin [14]. The $\mathrm{pH}$ value after 8 hours fermentation is quite nearer to range 4.4 to 4.6 and 4.3 to 4.5 for fermented soy product [15], [16]. 


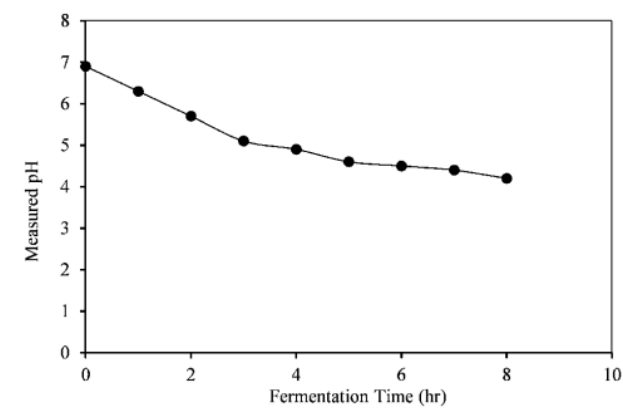

Fig. 2. pH change of yogurt made from $25 \%$ of cow milk $+75 \%$ of soy milk.

\section{Sensory Evaluation}

The sensory properties of developed yogurt samples were evaluated by the semi trained panelists. A structured 9 point hedonic scale was used to score individual parameters of each sample. The obtained result of sensory evaluation is shown in Table II.

TABLE II: SENSORY EVALUATION OF YOGURT MADE FROM DIFFERENT RATIO OF SOY AND COW MILK

\begin{tabular}{cccc}
\hline $\begin{array}{c}\text { Ratio of soy milk (SM) } \\
\text { and cow milk (CM) }\end{array}$ & $\begin{array}{c}\text { Taste and } \\
\text { flavor }\end{array}$ & $\begin{array}{c}\text { Texture or } \\
\text { consistency }\end{array}$ & $\begin{array}{c}\text { Overall } \\
\text { acceptabilit } \\
\text { y }\end{array}$ \\
\hline $100 \% \mathrm{CM}$ & $3.64 \pm 1.5^{\mathrm{a}}$ & $3.75 \pm 1.87^{\mathrm{a}}$ & $3.42 \pm 1.91^{\mathrm{a}}$ \\
$75 \% \mathrm{CM}+25 \% \mathrm{SM}$ & $4.79 \pm 1.7^{\mathrm{b}}$ & $7.47 \pm 0.88^{\mathrm{c}}$ & $4.85 \pm 1.81^{\mathrm{b}}$ \\
$50 \% \mathrm{CM}+50 \% \mathrm{SM}$ & $5.89 \pm 2.3^{\mathrm{c}}$ & $4.91 \pm 2.52^{\mathrm{b}}$ & $5.56 \pm 2.18^{\mathrm{c}}$ \\
$25 \% \mathrm{CM}+75 \% \mathrm{SM}$ & $7.86 \pm 1.32^{\mathrm{d}}$ & $5.72 \pm 1.45^{\mathrm{c}}$ & $7.36 \pm 1.16^{\mathrm{d}}$ \\
$100 \% \mathrm{SM}$ & $6.71 \pm 1.52^{\mathrm{c}}$ & $6.82 \pm 2.1^{\mathrm{d}}$ & $6.71 \pm 2.5^{\mathrm{d}}$ \\
\hline \hline
\end{tabular}

The data are mean \pm S.D. a-d Letters indicates statistical difference at same time $(\mathrm{p}<0.05)$

It can be seen that, highest test and flavor score was secured by yogurt from $75 \%$ soy milk (rest is cow milk) where yogurt from $25 \%$ soy milk gave best texture or consistent product. However, based on sensory evaluation yogurt made from $25 \%$ cow milk $+75 \%$ soy milk was found to be best as it had highest score of overall acceptability. Interestingly, most participants preferred yogurt from 100\% soy milk over $100 \%$ cow milk

\section{CONCLUSION}

In addition of cherry fruit and extra virgin olive oil in bottom layer, a mixture of $75 \%$ soy milk and $25 \%$ cow milk was successfully used to produce functional fruit bottom yogurt. This produced yogurt had less dairy fat and more MUFA, PUFA as well as bioactive compounds. Fermentation of the developed product was satisfactory with probiotic Bifidobacterium starter. According to sensory evaluation, the functional yogurt made from a mixture of $75 \%$ soy and $25 \%$ cow milk with addition of gelatin found to be most acceptable. Further research is suggested to evaluate physicochemical and storage stability before commercialization of the developed product.

\section{REFERENCES}

[1] G. Ghoneem, M. Ismail, N. El-Boraey, M. Tabekha, and H. Elashrey, "Optimal Combination of Soy, Buffalo, and Cow's Milk in Bioyogurt for Optimal Chemical, Nutritional, and Health Benefits," J. Am. Coll. Nutr., vol. 37, no. 1, pp. 8-16, 2018.

[2] A. Martí et al., "Yogurt consumption and abdominal obesity reversion in the PREDIMED study," Nutr. Metab. Cardiovasc. Dis., vol. 26, no. 6, pp. 468-475, 2015.

[3] S. Sengupta, R. Goswami, S. Basu, and J. Bhowal, "Hypolipidemic effects of soy yogurt fortified with antioxidant rich vegetable oil on albino mice fed high cholesterol diet," Mater. Today Proc., vol. 3, no. 10, pp. 3222-3237, 2016.

[4] S. Mishra Pandey and H. N. Mishra, "Optimization of the prebiotic \& probiotic concentration and incubation temperature for the preparation of synbiotic soy yoghurt using response surface methodology," $L W T$ Food Sci. Technol., vol. 62, no. 1, pp. 458-467, 2015.

[5] O. Eslami and F. Shidfar, "Soy milk: A functional beverage with hypocholesterolemic effects? A systematic review of randomized controlled trials," Complement. Ther. Med., vol. 42, no. September 2018, pp. 82-88, 2019

[6] N. F. Fazilah, A. B. Ariff, M. E. Khayat, L. Rios-Solis, and M. Halim, "Influence of probiotics, prebiotics, synbiotics and bioactive phytochemicals on the formulation of functional yogurt," J. Funct. Foods, vol. 48, no. April, pp. 387-399, 2018.

[7] I. Ścibisz, M. Ziarno, M. Mitek, and D. Zareba, "Effect of probiotic cultures on the stability of anthocyanins in blueberry yoghurts," $L W T$ - Food Sci. Technol., vol. 49, no. 2, pp. 208-212, 2012.

[8] S. H. Nile and S. W. Park, "Edible berries: Bioactive components and their effect on human health," Nutrition, vol. 30, no. 2, pp. 134-144, 2014.

[9] A. Foscolou, E. Critselis, and D. Panagiotakos, "Olive oil consumption and human health: A narrative review," Maturitas, vol. 118, no. October, pp. 60-66, 2018.

[10] B. Dal Bello, L. Torri, M. Piochi, and G. Zeppa, "Healthy yogurt fortified with n-3 fatty acids from vegetable sources," J. Dairy Sci., vol. 98 , no. 12, pp. 8375-8385, 2015

[11] J. D. Estrada, C. Boeneke, P. Bechtel, and S. Sathivel, "Developing a strawberry yogurt fortified with marine fish oill," J. Dairy Sci., vol. 94 , no. 12 , pp. 5760-5769, 2011.

[12] M. J. Oliveras-López, G. Berná, E. Jurado-Ruiz, H. López-García de la Serrana, and F. Martín, "Consumption of extra-virgin olive oil rich in phenolic compounds has beneficial antioxidant effects in healthy human adults," J. Funct. Foods, vol. 10, pp. 475-484, 2014.

[13] C. Xiang, Z. Xu, J. Liu, T. Li, Z. Yang, and C. Ding, "Quality, composition, and antioxidant activity of virgin olive oil from introduced varieties at Liangshan," LWT - Food Sci. Technol., vol. 78, pp. 226-234, 2017.

[14] A. N. Rinaldoni, M. E. Campderrós, and A. Pérez Padilla, "Physicochemical and sensory properties of yogurt from ultrafiltreted soy milk concentrate added with inulin," LWT - Food Sci. Technol., vol. 45, no. 2, pp. 142-147, 2012.

[15] C. F. G. da SILVA, F. L. SANTOS, L. R. R. de SANTANA, M. V. L SILVA, and T. de A. CONCEIÇÃO, "Development and characterization of a soymilk Kefir-based functional beverage," Food Sci. Technol., vol. 2061, no. AHEAD, p. 0, 2018.

[16] D. J. Park, S. Oh, K. H. Ku, C. Mok, S. H. Kim, and J. Y. Imm, "Characteristics of yogurt-like products prepared from the combinaton of skim milk and soymilk containing saccharified-rice solution," Int. J. Food Sci. Nutr., vol. 56, no. 1, pp. 23-34, 2005. 